\title{
A EVOLUÇÃO DAS EMISSÕES VEICULARES NO ESTADO DE SÃO PAULO: UMA NOVA ABORDAGEM NO PERÍODO DE 2009 A 2012
}

\author{
Cristiane Dias ${ }^{1}$;Marcelo Pereira Bales ${ }^{1}$ e Silmara Regina da Silva ${ }^{1}$ \\ ${ }^{1}$ CETESB (Companhia Ambiental do Estado de São Paulo) \\ E-mails:cdias@sp.gov.br, mbales@sp.gov.br, silmsilva@sp.gov.br
}

\section{RESUMO}

A CETESB (Companhia Ambiental do Estado de São Paulo) adotou, a partir de 2010, a metodologia proposta no 1‥ Inventário Nacional de Emissões Atmosféricas por Veículos Automotores Rodoviários (MMA, 2011) para o cálculo de estimativas de emissões veiculares no Estado de São Paulo e nas Regiões Metropolitanas. Os dados originados do PROCONVE e do PROMOT foram empregados para estimar as emissões da frota circulante, considerando as categorias de automóveis, comerciais leves ciclos Otto e Diesel, motocicletas, ônibus e caminhões.Em 2012, foi lançado o 1‥ Relatório“Emissões Veiculares no Estado de São Paulo" da CETESB, com amplo conteúdo e apresentando as estimativas de emissões de poluentes atmosféricos e de alguns Gases de Efeito Estufa (GEE) do ano de 2011. O objetivo deste trabalho é apresentar a evolução das emissões veiculares no período de 2009 a 2012. Os resultados demonstram que apesar do aumento da frota circulante e do consumo de combustível, a emissão de poluentes locais vem se mantendo estável, já que a substituição de veículos mais antigos por novos incorpora as tecnologias de controle atuais que promovem a emissão menor. No caso dosgases do efeito estufa (GEE), os resultados demonstram aumento na emissão, causados principalmente pelo aumento do consumo de gasolina C em substituição ao etanol hidratado.

\section{INTRODUÇÃO}

Em2010 a CETESB (Companhia Ambiental do Estado de São Paulo) adotou a metodologia apresentada no 1‥ Inventário Nacional de Emissões Atmosféricas por Veículos Automotores Rodoviários (MMA, 2011) [1] para o cálculo das emissões de poluentes regulamentados e Gases de Efeito Estufa de origem veicular. Em 2012 foi lançado o 1‥ Relatório "Emissões Veiculares no Estado de São Paulo" da CETESB [2] de acordo com a nova metodologia, apresentando as estimativas de emissões de poluentes atmosféricos e de alguns Gases de Efeito Estufa (GEE) relativos ao ano de 2011.

Em 2013 foi publicada a versão referente ao ano de 2012, mas com dados de emissão retroagindo à 2009, seguindo as mesmas metodologias. Dessa forma, é possível observar a evolução, ainda que em um pequeno intervalo de tempo, dos fenômenos ligados às emissões veiculares. 
Esta metodologia permitiu observar a influência dos veículos em circulação, excluindo os veículos com baixa probabilidade de sobrevivência em função da data de fabricação.Utilizamos as curvas de sucateamento fornecidas por estudos do Ministério de Ciência e Tecnologia em 2006 [3], para as seguintes categorias de veículos consideradas: automóveis, comerciais leves ciclos Otto e Diesel, motocicletas, ônibus e caminhões.

Os valores de vendas anuais de veículos novos, leves e pesados, foramfornecidos pela ANFAVEA[4] (Associação Nacional dos Fabricantes de Veículos Automotores) para o Estado de São Paulo e a ABRACICLO [5] (Associação Brasileira dos Fabricantes de Motocicletas, Ciclomotores, Motonetas, Bicicletas e Similares) disponibilizou os valores correspondentes às motocicletas.

Para o cálculo da frota circulante das Regiões Metropolitanas foi adotada a mesma proporção de sucateamento por categoria do Estado de São Paulo, mas aplicada à frota registrada pelo Detran/SP.

Foram empregadas estimativas de intensidade de uso de referência ouquilometragem anual percorrida por categoria mais próximas da realidade, variando em função da idade do veículo. A partir dos valores de intensidade de uso de referência e do volume de combustíveis consumidos no Estado de São Paulo e nas Regiões Metropolitanas, foi realizado o ajuste da intensidade de uso ou da quilometragem anual percorrida.

A equação 1 é a geral utilizada para o cálculo das emissões de escapamento de uma frota circulante, por poluente e ano modelo de veículo.

Onde:

$$
\mathrm{E}=\mathrm{Fr} \times \mathrm{lu} \times \mathrm{Fe} \text { (equação 1) }
$$

E - taxa anual de emissão do poluente (g/ano);

$\mathrm{Fr}$ - frota circulante de veículos, considerando o ano de interesse;

lu - intensidade de uso ou quilometragem anual percorrida pelo veículo (km/ano);e

$\mathrm{Fe}$ - fator de emissão do poluente considerado, em g/km.

Existem inúmeras incertezas relacionadas ao cálculo de emissões veiculares, onde se pode destacar: a indisponibilidade de fatores de emissão de veículos em uso, a influência das condições de manutenção dos veículos, a melhoria dos dados de intensidade de uso ou quilometragem anual percorrida, principalmente para os veículos pesados, etc.

\section{INFORMAÇÕES GERAIS}

Os poluentes inventariados foram o monóxido de carbono (CO), os hidrocarbonetos não-metano (NMHC), incluindo as emissões evaporativas, os óxidos de nitrogênio $\left(\mathrm{NO}_{\mathrm{x}}\right)$, o material particulado (MP), o dióxido de enxofre $\left(\mathrm{SO}_{2}\right)$ e os aldeídos ( $\mathrm{RCHO}$ );e também os seguintes gases de efeito estufa (GEE): o dióxido de carbono $\left(\mathrm{CO}_{2}\right)$, o metano $\left(\mathrm{CH}_{4}\right)$ e o $\mathrm{N}_{2} \mathrm{O}$ (óxido nitroso). Também foi estimada a emissão de dióxido de carbono equivalente, $\mathrm{CO}_{2 \text { eq }}$, que equipara o potencial de aquecimento global dos GEE pelo conceito do potencial de aquecimento global (GWP). Não foram 
consideradas as emissões de $\mathrm{CO}_{2}$ oriundas dos combustíveis renováveis, o etanol hidratado, etanol anidro e biodiesel, de acordo com a metodologia de contabilização de GEE adotada na Política Estadual de Mudanças Climáticas do Estado, que segue a recomendação do IPCC(Painel Intergovernamental de Mudanças Climáticas)[6].

Para a maioria dos poluentes, as emissões veiculares foram estimadas utilizando a abordagem "bottom-up", na qual se considera a distância anual percorrida pelo veículo e dados específicos para o cálculo das emissões. Com exceção do $\mathrm{CO}_{2} \mathrm{e}$ do $\mathrm{SO}_{2}$, para todas as categorias, e $\mathrm{CH}_{4}$ e $\mathrm{N}_{2} \mathrm{O}$, para o ciclo Diesel, onde foi empregada a abordagem "top-down", devido à ausência de fatores de emissão específicos.

\section{FROTA CIRCULANTE}

A frota circulante do Estado de São Paulo, para o período de 2009 a 2012, obtida deacordo com os critérios da nova metodologia é apresentada nafigura 1 . O número de automóveis do ciclo Otto é muito superior ao número de veículos do ciclo Diesel e de motocicletas. Entretanto, o crescimento da frota de veículos do ciclo Otto foi de $12 \%$ de 2009 a 2012, enquanto as frotas circulantes do ciclo Diesel e de motocicletas apresentaram crescimentos de $17 \%$ e $16 \%$, respectivamente.

Figura 1. Estimativas da frota circulante no Estado de São Paulo, de 2009 a 2012

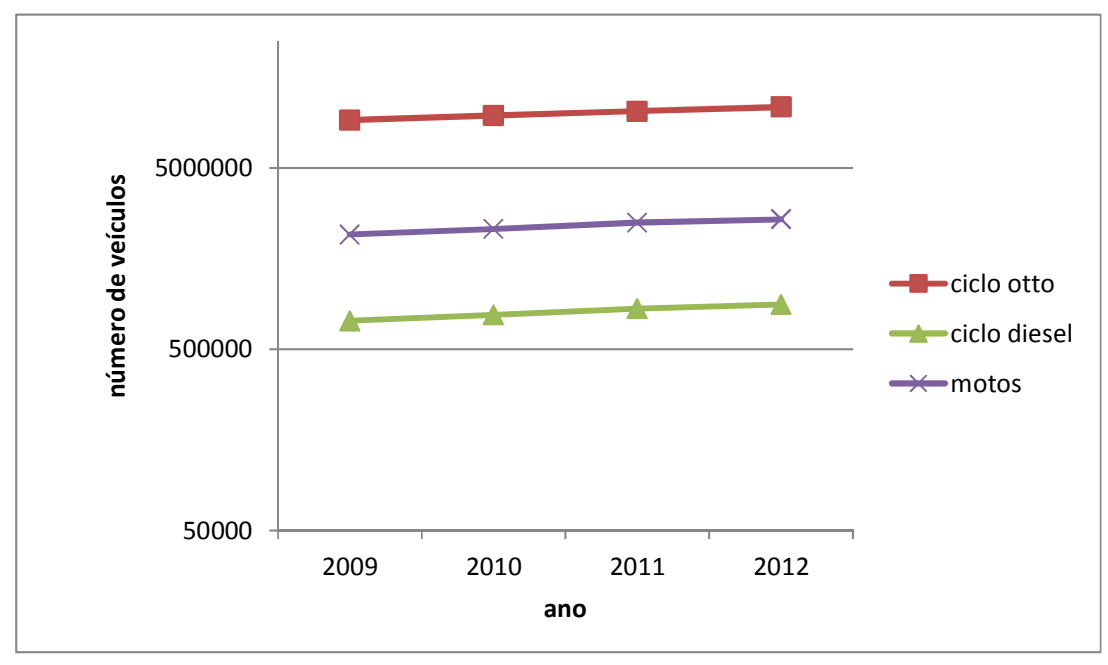

Na figura 2, considerando a Região Metropolitana de São Paulo, pode-se observar que o perfil das frotas circulantes dos automóveis ciclos Otto, Diesel e das motocicletas é semelhante ao perfil de frota encontrado para o Estado de São Paulo. O crescimento da frota de automóveis do ciclo Otto foi de $12 \%$ de 2009 a 2012, enquanto as frotas circulantes do ciclo Diesel e de motocicletas apresentaram crescimentos de $20 \%$ e $21 \%$, respectivamente. 
Figura 2. Estimativas da frota circulante na Região Metropolitana de São Paulo, de 2009 a 2012

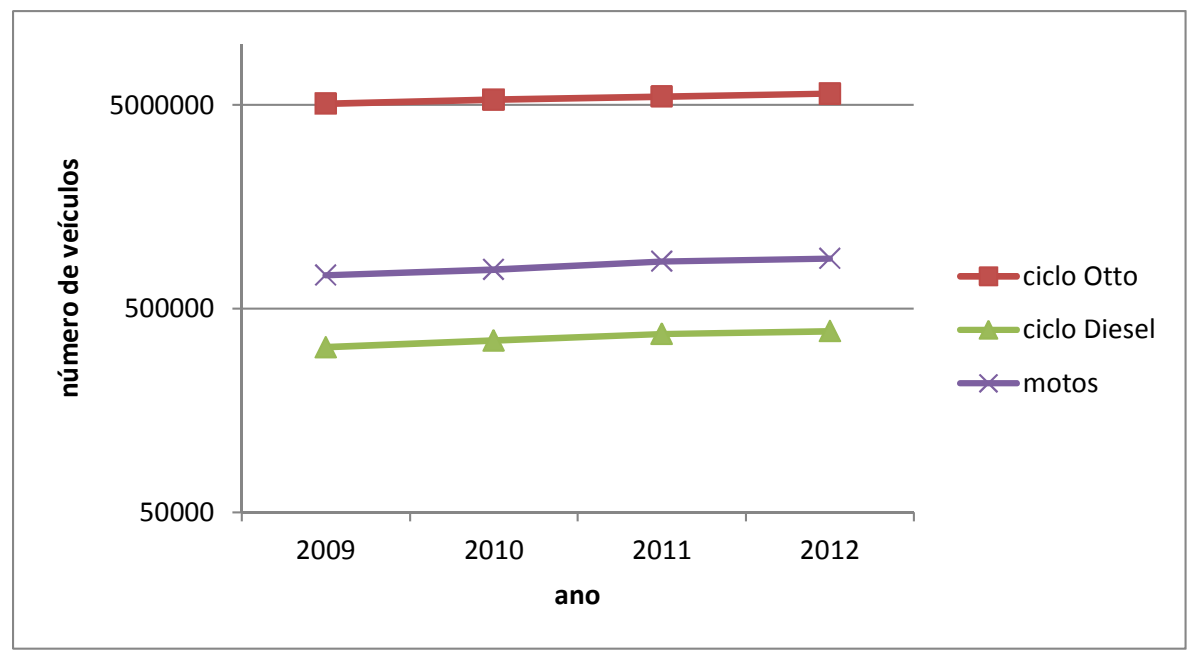

\section{CONSUMO DE COMBUSTÍVEL}

As emissões veiculares variam principalmente em função da frota circulante e do volume de combustível (Gasolina C, Etanol Hidratado e Diesel), uma vez que a intensidade de uso é ajustada pelo total de combustível consumido.

Para o cálculo das estimativas das emissões veiculares, foram utilizados os dados de consumo rodoviário de combustíveis fornecidos pela ANP (Agência Nacional do Petróleo, Gás Natural e Biocombustíveis) [7] e mostrados na tabela 1.

Tabela 1. Consumo de combustíveis de uso rodoviário no Estado de São Paulo

\begin{tabular}{|c|c|c|c|c|}
\hline \multirow{2}{*}{ Combustível } & \multicolumn{4}{|c|}{ Consumo anual em bilhões de litros } \\
\cline { 2 - 5 } & $\mathbf{2 0 0 9}$ & $\mathbf{2 0 1 0}$ & $\mathbf{2 0 1 1}$ & $\mathbf{2 0 1 2}$ \\
\hline Gasolina C & 6,7 & 7,4 & 9,5 & 10,3 \\
\hline Etanol Hidratado & 8,6 & $\mathbf{8 , 4}$ & 6,5 & 5,8 \\
\hline Óleo Diesel & 7,1 & 7,4 & 7,8 & 8,22 \\
\hline
\end{tabular}

Fonte: Adaptado ANP

\section{ANÁLISE DOS RESULTADOS}

A figura 3 indica a evolução do total das emissões de CO no Estado de São Paulo, em toneladas, de 2009 a 2012. Os veículos automotores do ciclo Otto são responsáveis pela maior parcela das emissões de $\mathrm{CO}$ e apresentaram uma redução de $19 \%$ nas emissões. As motocicletas apresentarama redução de $10 \%$ e os veículos do cicloDieseltiveram o aumento de apenas $2 \%$ na emissão de monóxido de carbono nesse período. 
Figura 3. Evolução do Total das emissões de monóxido de carbono, em toneladas, no Estado de São Paulo de 2009 a 2012

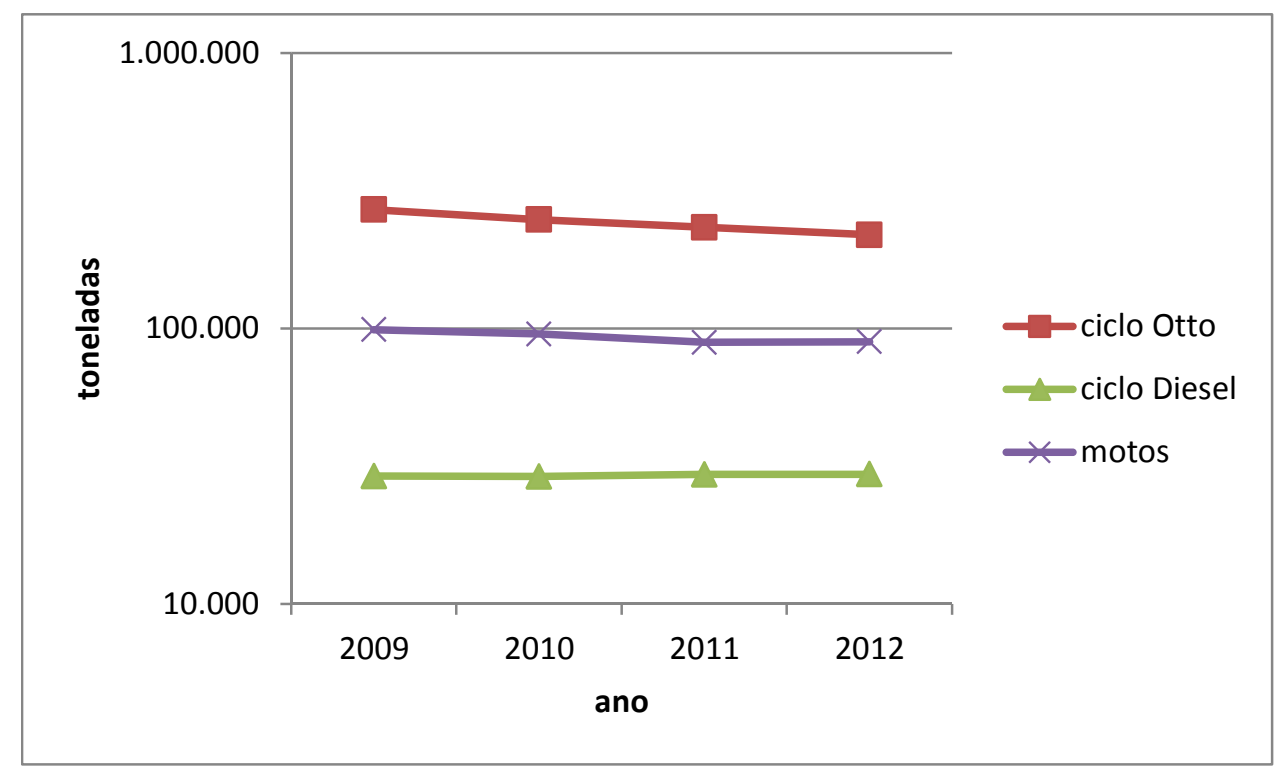

A figura 4 mostra a evolução das emissões de hidrocarbonetos não-metano (NMHC), incluindo as emissões evaporativas para automóveis e comerciais leves do ciclo Otto. Houve redução de 17\% nas emissões de NMHCdo ciclo Otto e a redução de $9 \%$ nas emissões de NMHC dos veículos do cicloDiesel. As motocicletas indicaram a redução de $6 \%$ em suas emissões.

Figura 4. Evolução do Total das emissões de hidrocarbonetos não-metano em toneladas, no Estado de São Paulo de 2009 a 2012

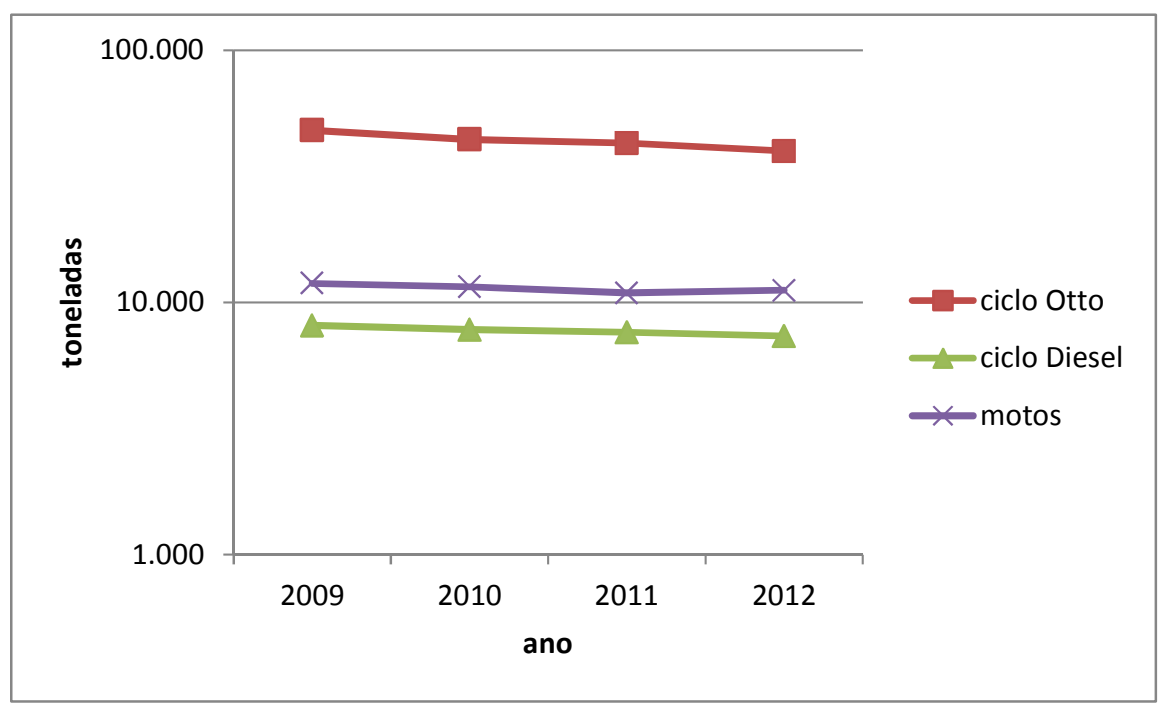

Como indica a figura 5 , os veículos do cicloDiesel são os maiores responsáveis pelas emissões de $\mathrm{NO}_{x}$, com o aumento de apenas $2 \%$ em suas emissões. Para os veículos do cicloOtto, houve a redução de 15\% nas emissões, de 2009 a 2012. As motocicletas apresentaram um aumento de $40 \%$ das suas emissões de $\mathrm{NO}_{\mathrm{x}}$. 
Figura 5. Evolução do Total das emissões de óxidos de nitrogênio em toneladas, no Estado de São Paulo de 2009 a 2012

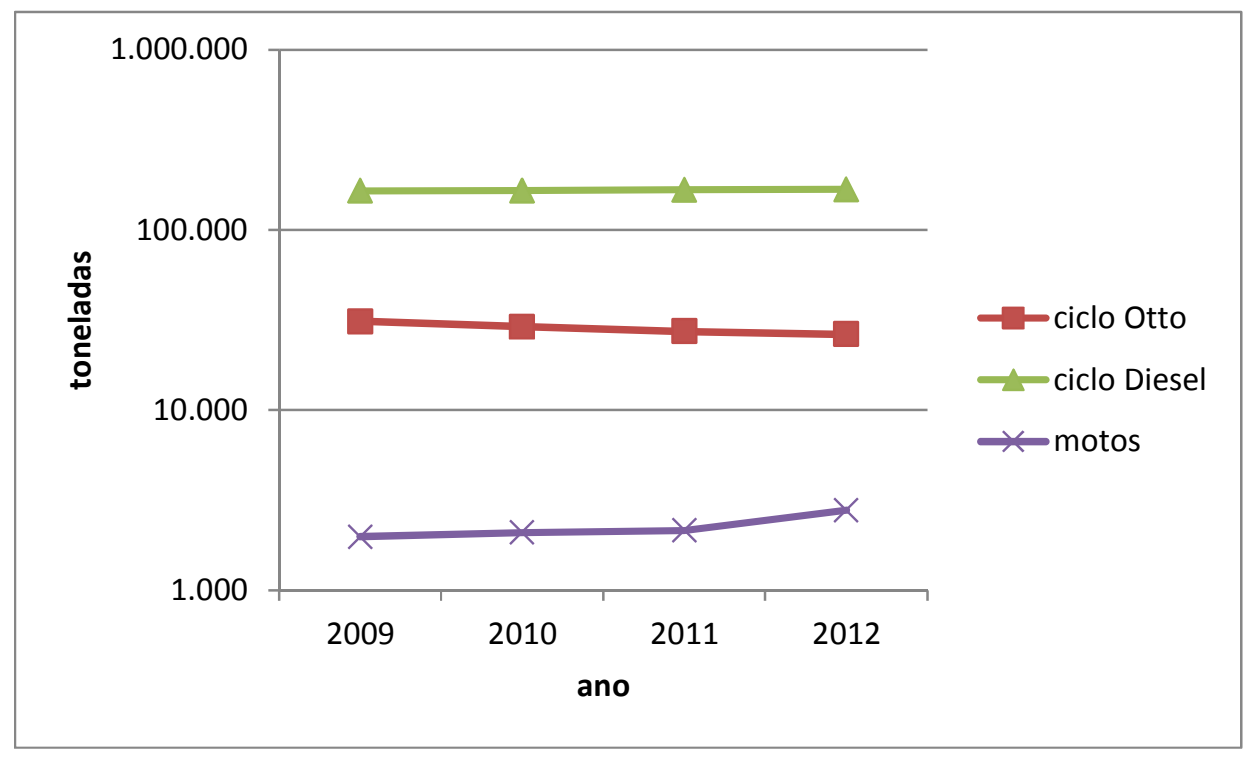

A figura 6 aponta que os veículos do cicloDiesel também são os maiores responsáveis pelas emissões de material particulado no Estado, mas pode-se observar a redução de $15 \%$ nas emissões. Para os veículos do cicloOtto, houve o aumento de $59 \%$, de 2009 a 2012 . As motocicletas apresentaram um aumento de $41 \%$ das suas emissões no período.

Figura 6. Evolução do Total das emissões de material particulado, em toneladas, no Estado de São Paulo de 2009 a 2012

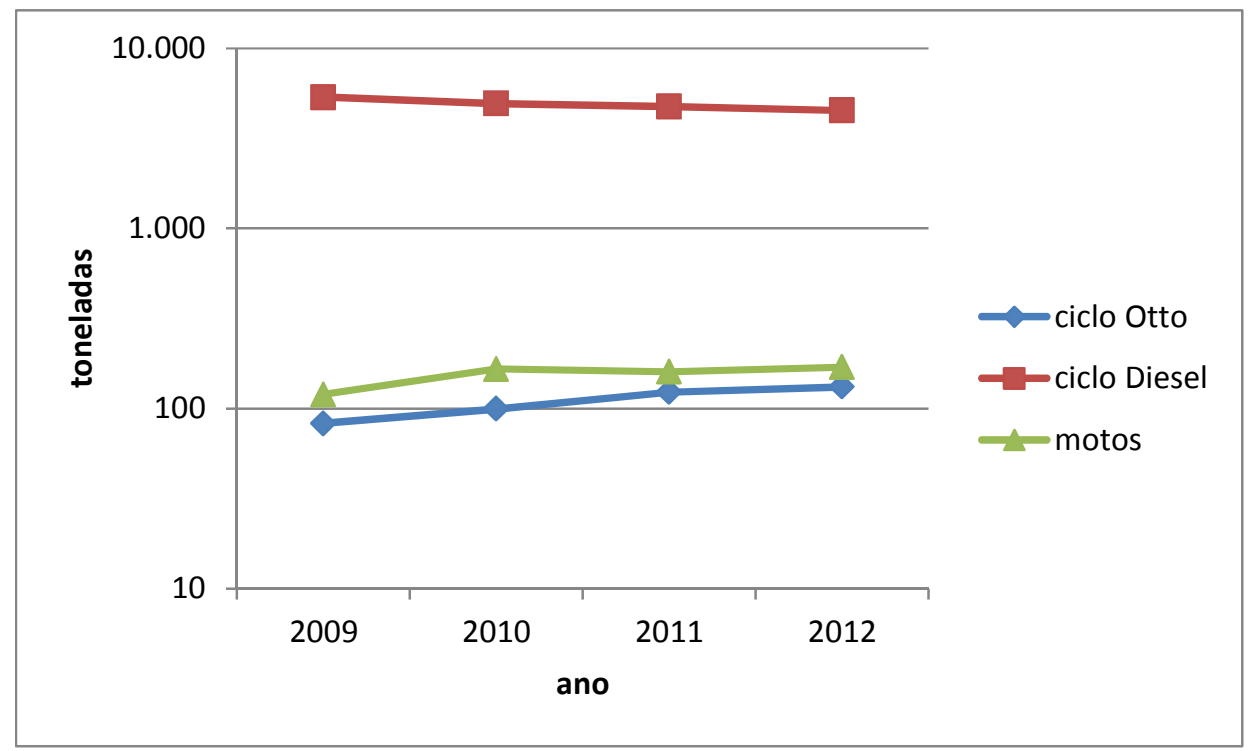


A figura 7 ilustra as emissões totais de $\mathrm{SO}_{2}$ dos veículos do cicloDiesel, Otto e das motocicletas. Para o cicloDiesel, observamoso aumento de 6\% nas emissões de $\mathrm{SO}_{2}$. Para o cicloOttohouveaumento de $55 \%$ nas emissões, de 2009 a 2012. As motocicletas apresentaram aumento de $36 \%$ das emissões neste período. Deve-se ressaltar que as emissões de $\mathrm{SO}_{2}$ foram obtidas pela abordagem "top-down", que estão totalmente relacionadas com o enxofre contido nos combustíveis fósseis.

Figura 7. Evolução do total das emissões de dióxido de enxofreem toneladas, no Estado de São Paulo de 2009 a 2012

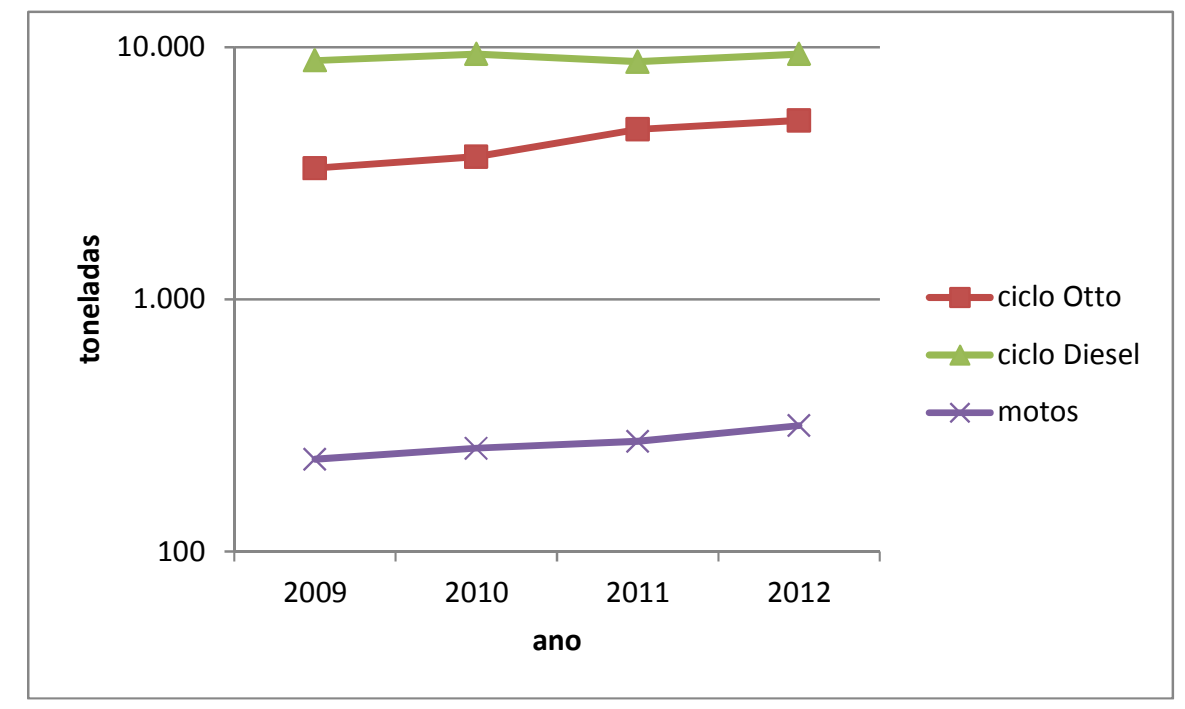

As emissões de aldeídos no Estado de São Paulo estão indicadas na figura 8, para veículos do cicloOtto. Houve a redução de $34 \%$ nas emissões dos aldeídos totais de 2009 a 2012.

Figura 8. Evolução das emissões de aldeídos totais, em toneladas, no Estado de São Paulo de 2009 a 2012

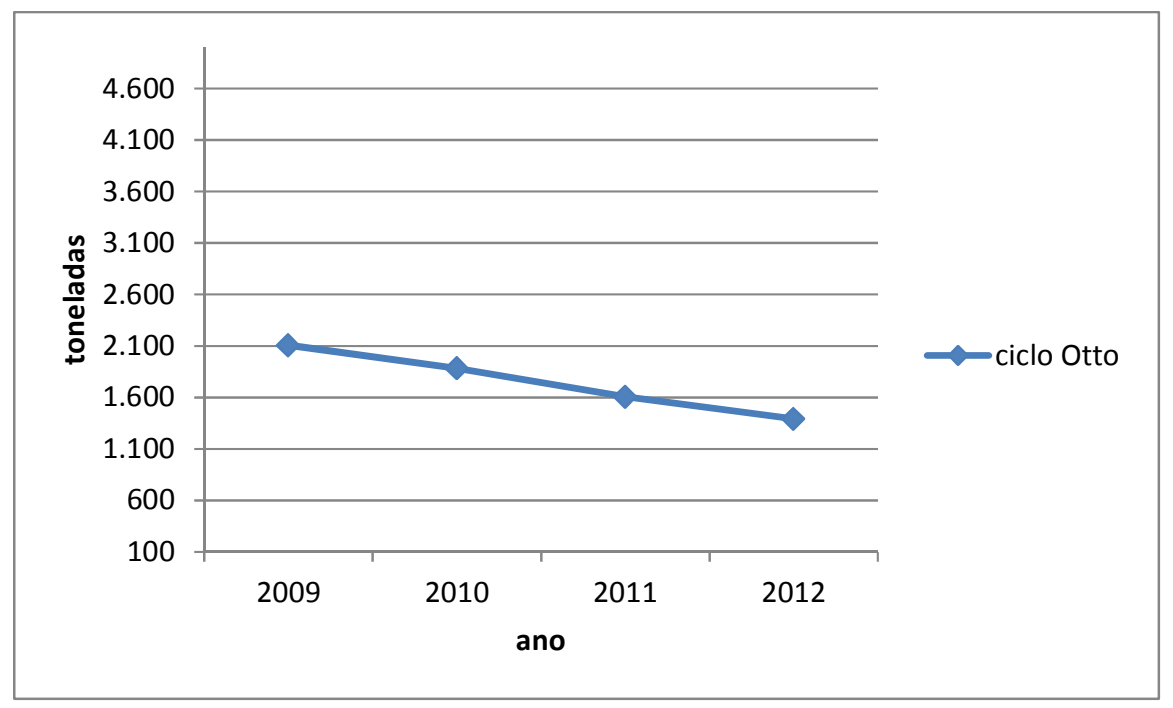


As emissões de $\mathrm{CH}_{4}$ para o Estado de São Paulo são apresentadas na figura 9. Para os veículos do cicloOtto, a abordagem usada para o cálculo das emissões foi a "bottom-up". Para os veículos do cicloDiesel e motocicletas, a abordagem foi a "topdown". Foram utilizados os fatores de emissão recomendados pelo IPCC. Houve aumento de $6 \%$ nas emissões totais de $\mathrm{CH}_{4}$ para os veículos do cicloOtto e o aumento de $14 \%$ para o cicloDiesel. As motocicletastiveram aumento de $42 \%$ nas emissões de $\mathrm{CH}_{4}$ no Estado de São Paulo, de 2009 a 2012.

Figura 9. Evolução do total das emissões de metano em toneladas, no Estado de São Paulo de 2009 a 2012

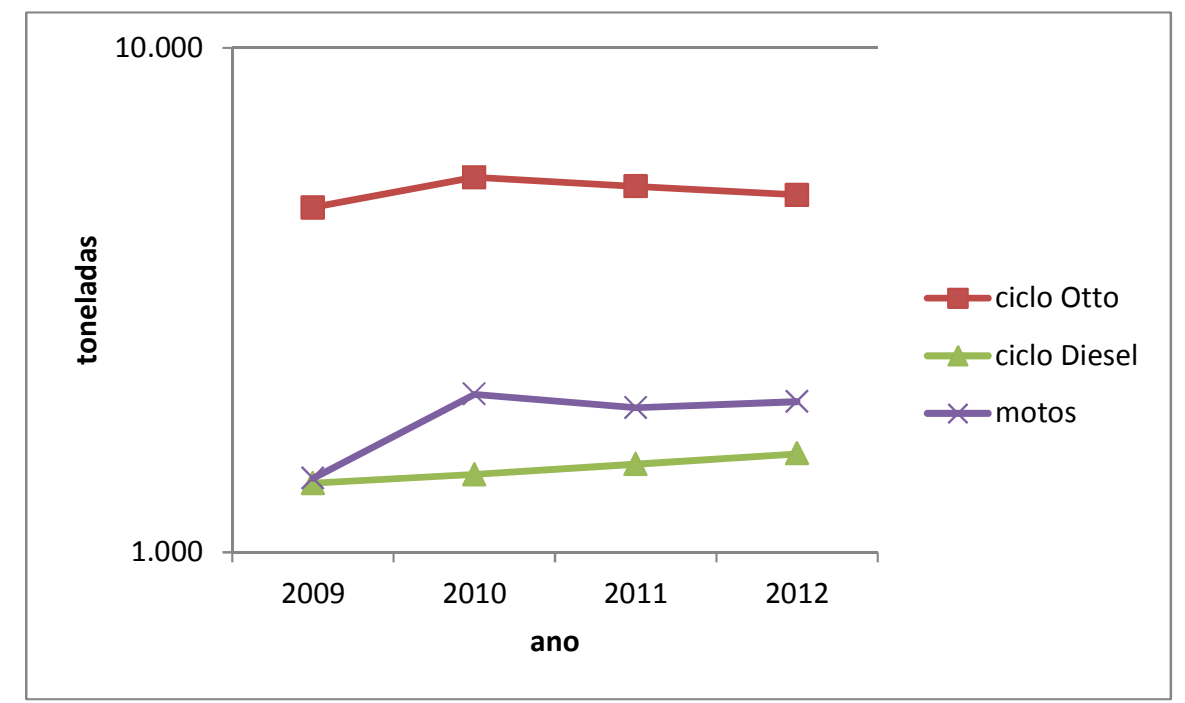

De acordo com a figura 10, as emissões totais de $\mathrm{N}_{2} \mathrm{O}$ no Estado de São Paulo aumentaram em 19\% de 2009 a 2012 para os veículos do cicloOtto. Houve também um aumento de $6 \%$ para os veículos do cicloDiesel e $28 \%$ para as motocicletas.

Figura 10. Evolução do total das emissões de óxido nitroso, em toneladas, no Estado de São Paulo de 2009 a 2012

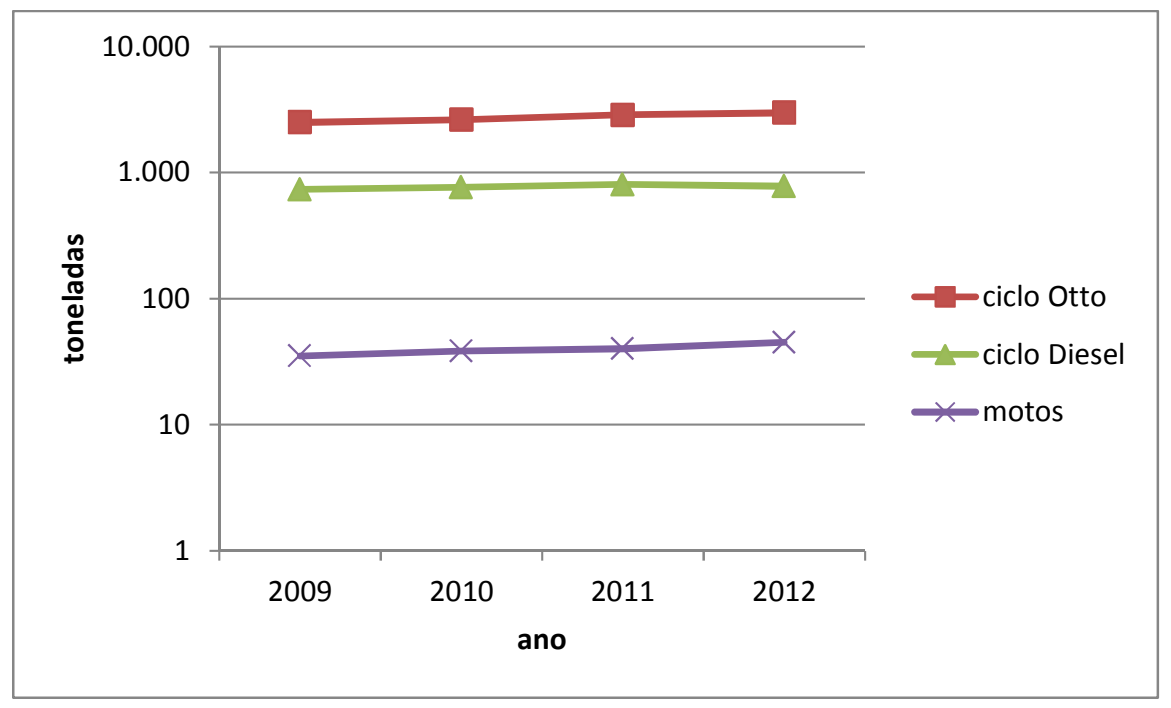




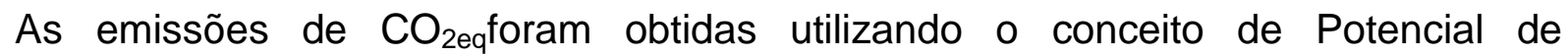
Aquecimento Global (GWP), para os gases $\mathrm{CH}_{4}, \mathrm{~N}_{2} \mathrm{O}$ e $\mathrm{CO}_{2}$ e para um horizonte de 100 anos [8]. Houve aumento de $33 \%$ nas emissões de $\mathrm{CO}_{2 e q}$ no Estado de São Paulo, de 2009 a 2012, como apontado na figura 11.Essa evolução é motivada pelo aumento da frota circulante, pelo aumento no consumo de combustível e principalmente pela redução do consumo de etanol hidratado, substituído pelo consumo de gasolinaC nos veículos flex-fuel.

Figura 11. Evolução do total das emissões de dióxido de carbono equivalente, em toneladas, no Estado de São Paulo de 2009 a 2012

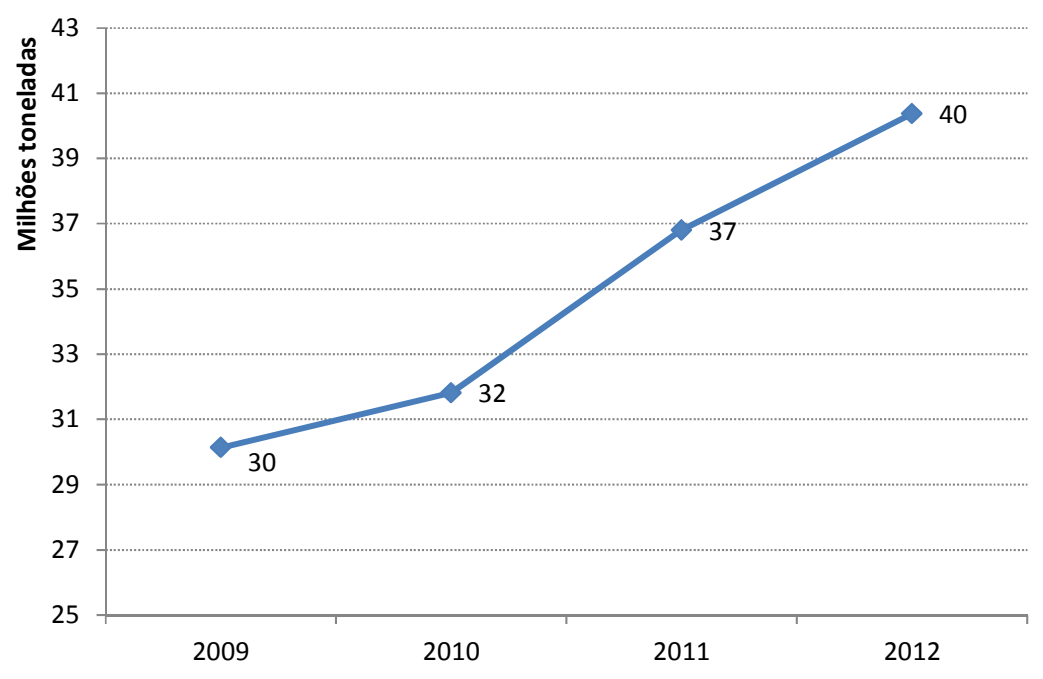

\section{INDICADORES}

Os resultados demonstrados permitem a definição de alguns indicadores que demonstram a evolução dos parâmetros de controle das emissões, da frota circulante e das questões correlatas.

\subsection{INDICADOR TECNOLÓGICO}

Esse indicador aponta para a evolução tecnológica da frota circulante, incorpora a renovação da mesma e aponta seu impacto nas emissões. A Figura 12 indica o comportamento do indicador tecnológico das emissões ao longo dos anos, para veículos leves e comerciais leves do ciclo Otto. Percebe-se que há um leve declínio nas emissões, exceto para MP. 
Figura 12 - Evolução do indicador tecnológico dos automóveis e comerciais leves do ciclo Otto no Estado de São Paulo

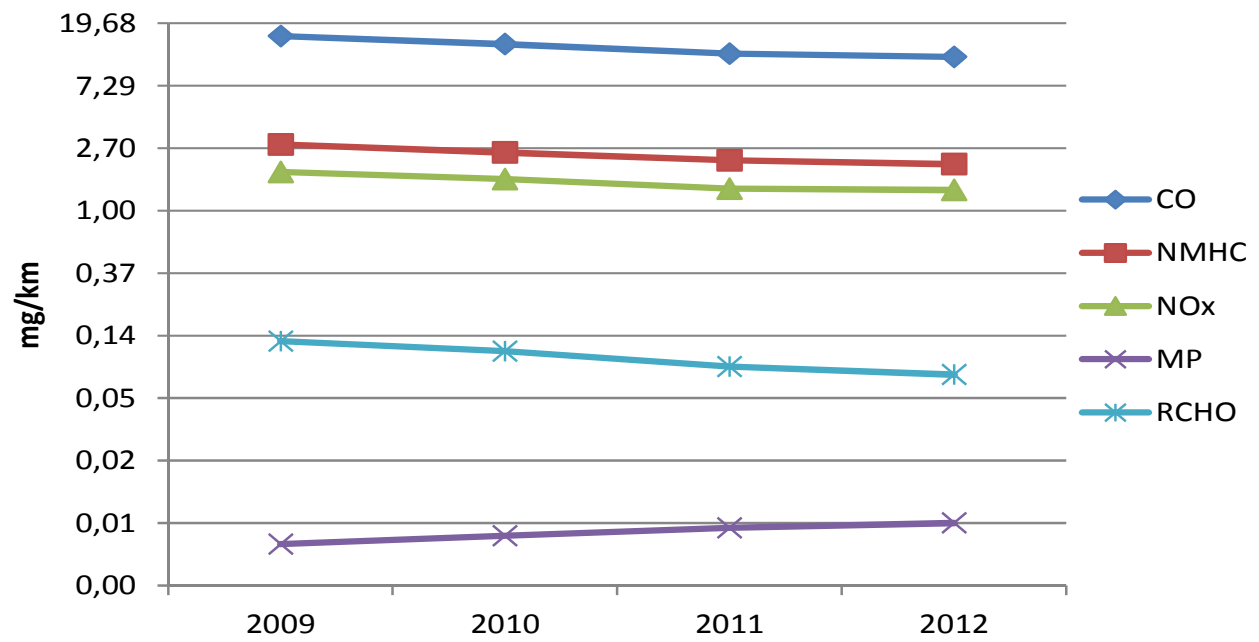

A Figura 13 mostra a evolução deste indicador no período de 2009 a 2012 para os comerciais leves e pesados do ciclo Diesel. A tendência de redução da emissão da frota circulante é bastante tênue. Provavelmente por causa da evolução mais lenta das fases do PROCONVE. Vale destacar que a Fase P6 de 2009 nem sequer foi implementada, tornando a Fase P5 mais longa, desde 2003 até a introdução da Fase P7 em 2012. Além disso, parte desta frota, no caso de caminhões, apresenta uma renovação natural mais lenta.

Figura 13 - Evolução do indicador tecnológico dos veículos comerciais leves e pesados do ciclo Diesel no Estado de São Paulo

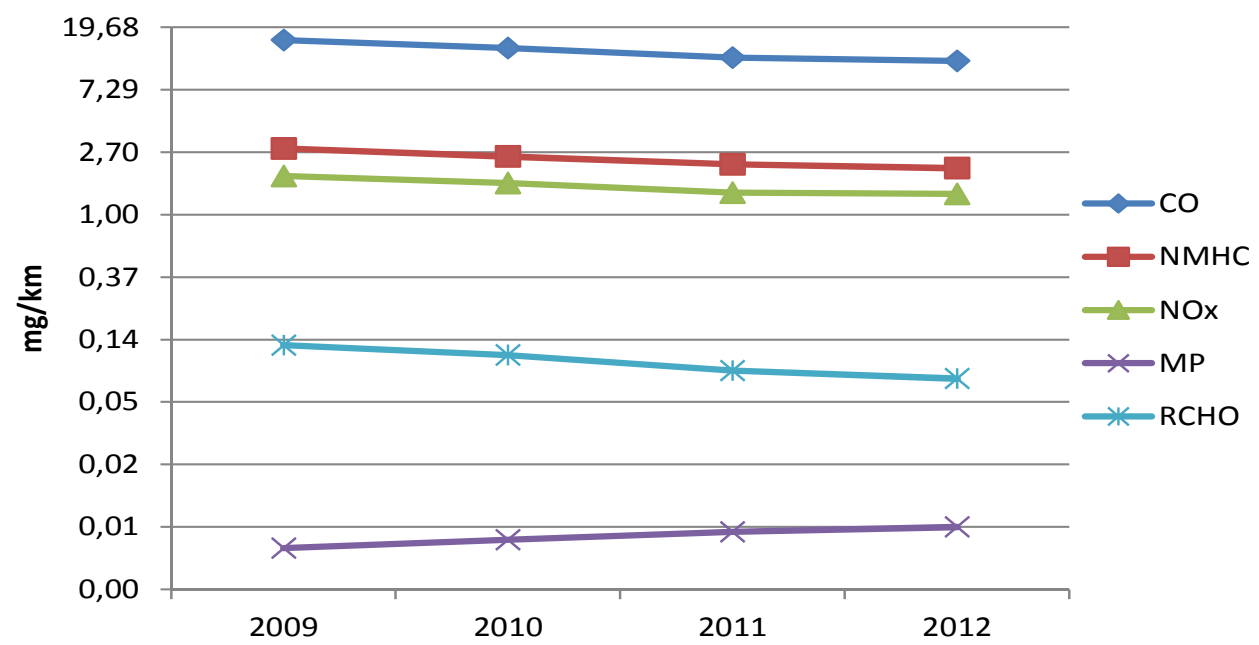


A Figura 14 mostra a evolução deste indicador no período de 2009 a 2012 para as motocicletas. A evolução da emissão é variável, crescente para alguns poluentes e decrescente para outros. Nesse período apresentado não houve mudanças tecnológicas com impacto significativo nas emissões dos motociclos.

Figura 14 - Evolução do indicador tecnológico das motocicletas no Estado de São Paulo

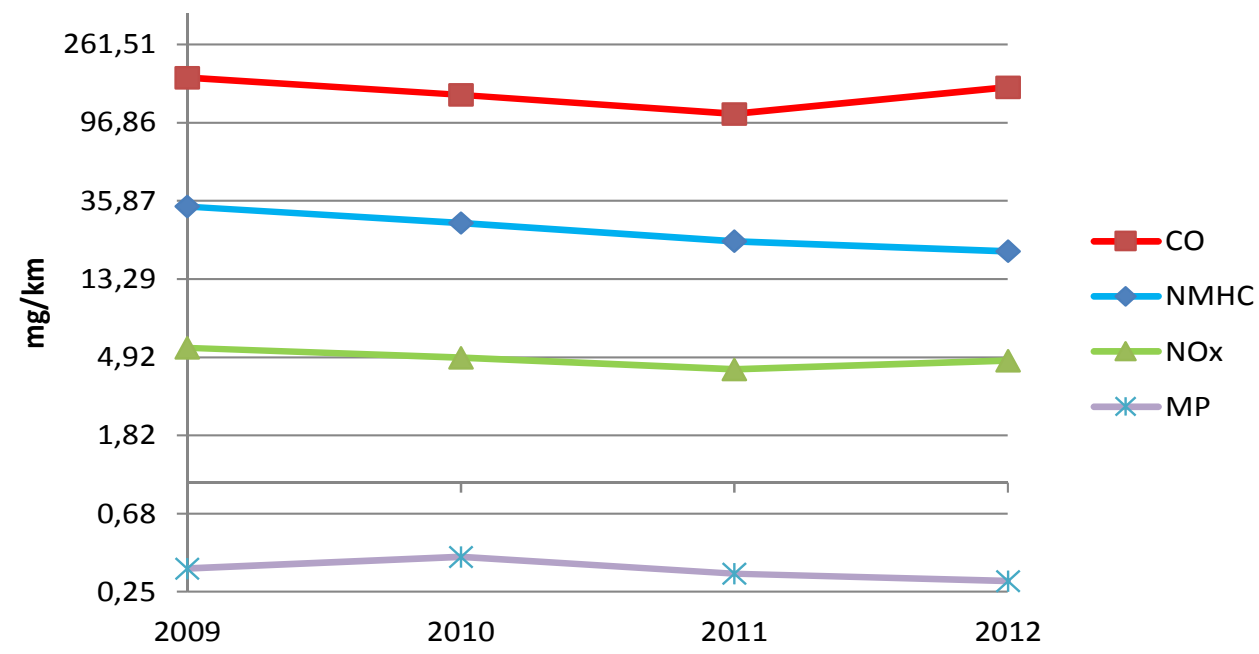

\section{CONCLUSÃo}

Os resultados das estimativas das emissões veiculares no Estado de São Paulo indicam que os veículos do cicloOtto, leves seguidos pelas motos, têm maior influência nas emissões de $\mathrm{CO}$ e NMHC, devido às características do motor e do número de veículos presentes na frota circulante do Estado de São Paulo e na Região Metropolitana de São Paulo. Mas os indicadores mostram uma tendência na redução da emissão desses poluentes nos segmentos mais emissores e a manutenção da emissão no segmento Diesel, apontando uma redução global nas emissões.

Os veículos do cicloDiesel apresentam maior influência nas emissões de $\mathrm{NO}_{x} \cdot \mathrm{A}$ curva de tendência não demonstra variação, embora se espere uma queda com a entrada dos veículos da fase P7 (pesados) do PROCONVE a partir de 2012 e a saída dos mais antigos, em um processo natural de renovação da frota circulante. No segmento Otto há uma pequena tendência de queda nas emissões.

Para o poluente MP também o segmento Diesel se mostra mais impactante e a tendência de queda se dará da mesma forma que para $\circ \mathrm{NO}_{x}$, com a renovação gradual da frota.

Os veículos Diesel ainda são os maiores emissores de $\mathrm{SO}_{2}$, mas seguidos de perto pelos veículos Otto. Como a emissão desse poluente está diretamente ligada ao teor de enxofre nos combustíveis, os processos de redução do teor de enxofre em curso é que levarão à redução das emissões, tanto para o Diesel quanto para a gasolina. 
As emissões de aldeídos totais foram determinadas apenas para os veículos do cicloOtto, pois ainda não há controle estabelecido para os veículos Diesel.A queda das emissões deste poluente pode ser atribuída à redução do uso de etanol hidratado, de 2009 a 2012.

De modo geral, as motocicletas apresentaram um aumento nas emissões de poluentes, devido ao crescimento da frota.

O aumento das emissões de dióxido de carbono equivalente $\left(\mathrm{CO}_{2 e q}\right)$ pode ser atribuído ao aumento do consumo de combustíveis fósseis (Gasolina $\mathrm{C}$ e Diesel) de 2009 a 2012.

Os indicadores tecnológicos mostram que a evolução das características da frota circulante é muito sutil, devido a lenta renovação. Para que os ganhos advindos dos padrões de emissão mais recentes se mostrem significativos, podem ser necessárias políticas mais incisivas de renovação, em especial com a retirada dos veículos mais antigos de circulação.

\section{REFERÊNCIAS}

[1] Ministério do Meio Ambiente. Inventário Nacional de Emissões Atmosféricas por Veículos Automotores Rodoviários - Relatório Final, Brasília, 2011.

[2] Companhia Ambiental do Estado de São Paulo - CETESB. Relatório de Emissões Veiculares no Estado de São Paulo, São Paulo, 2011.

[3] Ministério da Ciência e Tecnologia. Primeiro Inventário Brasileiro de Emissões Antrópicas de Gases de Efeito Estufa. Relatório de Referência: Emissões de Gases de Efeito Estufa no Setor Energético por Fontes Móveis, 2006.

[4] Associação Nacional dos Fabricantes de Veículos Automotores - ANFAVEA. Anuário da Indústria Automobilística Brasileira. Edição 2012. Disponível em <http:॥ www.anfavea.com.brlanuario.html> Acesso em 20/01/2012.

[5] Associação Brasileira dos Fabricantes de Motocicletas, Ciclomotores, Motonetas, Bicicletas e Similares - ABRACICLO. Anuário da Indústria Brasileira de Motociclos 2012. Disponível em <http:॥ www.abraciclo.com.br> Acesso em 16/03/2012.

[6] IPCC. 2006 IPCC Guidelines for National Greenhouse Gas Inventories. Prepared by the National Greenhouse Gas Inventories Programme, Eggleston H.S., Buendia L., Miwa K., Ngara T. and Tanabe K. (eds). Published:GES, Japan, 2006.

[7] Agência Nacional do Petróleo, Gás Natural e Biocombustíveis - ANP, Dados Estatísticos. Disponível em <http:॥ www.anp.gov.br> Acesso em 01/04/2013.

[8] Companhia Ambiental do Estado de São Paulo - CETESB. 1‥ Inventário de emissões antrópicas de gases de efeito estufa diretos e indiretos do Estado de São Paulo -Comunicação Estadual, São Paulo, 2011. 